\title{
La violación al ejercicio profesional de personas con síndrome de Down ${ }^{1}$
}

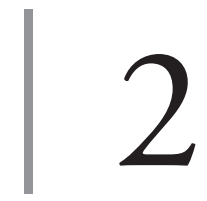

https://doi.org/10.21830/9789585284845.02

\author{
Paola Alexandra Sierra-Zamora ${ }^{2}$ \\ Vivian Lizbeth Arcos Cortés \\ María Paula Castro Alfonso ${ }^{4}$ \\ Universidad Católica de Colombia \\ Manuel Bermúdez-Tapia \\ Universidad Privada San Juan Bautista
}

\section{Introducción}

Este capítulo presenta el análisis de una relación entre fundamentos y criterios jurídicos que comprenden entre sí un conflicto de intereses entre el Estado colombiano y los ciudadanos. De esta manera, se evidencia cómo se viola y no se garantiza la igualdad del derecho al litigio para aquellas personas con síndrome de Down que aspiran a obtener un título de abogado y que,

1 Este capítulo hace parte de los resultados del proyecto de investigación "Desafíos contemporáneos para la protección de derechos humanos en escenarios de posconflicto desde enfoques interdisciplinarios - FASE II" del Grupo de Investigación Persona, Instituciones y Exigencias de Justicia, del Centro de Investigaciones Sociojurídicas, Facultad de Derecho, de la Universidad Católica de Colombia, registrado con el código COL0120899 de Minciencias. Los puntos de vista y los resultados de este artículo pertenecen a los autores y no reflejan necesariamente los de las instituciones participantes.

2 Abogada de la Universidad Católica de Colombia. Magíster en Derechos Humanos, Democracia y Justicia Internacional por la Universitat de València, España. PhD (c) del Programa de Derechos Humanos, Democracia y Justicia Internacional por la Universitat de València, España. Investigadora del Grupo de Investigación Persona, Instituciones y Exigencias de Justicia, de la Universidad Católica de Colombia. Orcid: https://orcid.org/0000-0002-3146-7418 - Contacto: pasierra@ucatolica.edu.co

3 Estudiante de Derecho de la Universidad Católica de Colombia. Contacto: vlarcos18@ ucatolica.edu.co

4 Estudiante de Derecho de la Universidad Católica de Colombia. Contacto: mpcastro04@ ucatolica.edu.co

5 Abogado de la Pontificia Universidad Católica del Perú (magna cum laude). Profesor-investigador de la Universidad Privada San Juan Bautista y profesor de la Facultad de Derecho de la Universidad Nacional Mayor de San Marcos. Consultor en temas de reforma del sistema de justicia en el Perú para el Banco Mundial, el Congreso de la República, el Poder Judicial y la Academia de la Magistratura. Orcid: https:// orcid.org/0000-0003-1576-9464 - Contacto: manuel.bermudez@upsjb.edu.pe 
aunque gozan de plena capacidad para el ejercicio de esta profesión, se ven imposibilitadas de ejercer la libre determinación de escoger profesión u oficio al ser declaradas interdictas por tener síndrome de Down. Como lo menciona Jurado,

no todos los individuos de la especie humana tienen capacidad legal o de ejercicio y por ello el ordenamiento los considera incapaces, se han ideado medidas para proteger sus derechos, puesto que al no cumplir con uno de los elementos estructurales del acto jurídico como lo es precisamente la capacidad, los contratos que celebre adolecerán de nulidad absoluta, por lo que se frustran sus efectos. Una de estas medidas es la denominada interdicción, que con la Ley 1306 de 2009, funge además como "una medida de restablecimiento de los derechos del discapacitado", y en consecuencia, cualquier persona podrá solicitarla. (2014, p. 17)

De lo anterior nace precisamente la perplejidad de entender si la interdicción cumple una función de restituir el derecho o si, por el contrario, es una máscara para la violación propia de los derechos que les son vulnerados a las personas declaradas interdictas. De acuerdo con Borea,

la capacidad jurídica es la pieza fundamental para el disfrute de los derechos. De ésta depende la posibilidad de crear una vida y un destino de acuerdo a la voluntad, convicción e ideologías propias. Esta es la llave para desarrollarse como persona e interactuar con el universo a través de: (i) derechos contractuales (por ejemplo, abrir una cuenta bancaria, mantener y manejar propiedades, alquilar una propiedad, comprar inmuebles); (ii) derechos políticos (por ejemplo, votar y postular en las elecciones del país) e, inclusive, (iii) para ejercer derechos personalísimos (por ejemplo, casarse y formar una familia). (2015, p. 168)

En consecuencia, dicha capacidad jurídica se hace inherente a esta libertad o independencia: la capacidad de autogobernarse y las responsabilidades que esto conlleva. Como afirma Fernández:

La autonomía es uno de los principios universales en los que se cimientan los derechos humanos. La Convención reconoce la autonomía individual y la independencia de las personas con discapacidad como el primero de sus principios rectores de acuerdo con la noción de que la autonomía individual es la condición previa para el ejercicio de derechos, un derecho universal inalienable que no puede restringirse por motivos de discapacidad. (2010, p. 14) 
Es precisamente lo anterior lo que contrapone los intereses del Estado colombiano con los de los ciudadanos, puesto que, si bien la interdicción es una figura que despliega una multiplicidad de violaciones, también es cierto que es una pieza fundamental para la valoración de los derechos de las personas con esta condición. Según lo menciona Pérez Carbajal y Campusano, la interdicción

tiene por objeto la protección de la persona y los bienes del mayor de edad que ha caído en estado de incapacidad [...], esto es porque se encuentra disminuido o perturbado en su inteligencia, padezca alguna afección originada por enfermedad o deficiencia persistente de carácter físico, psicológico o sensorial, como se señaló con anterioridad, designándole a esa persona incapaz un tutor y un curador, para atender debidamente todas sus necesidades y la administración de su patrimonio, toda vez que no puede gobernarse por sí misma. (2019, p. 237)

Es así, como finalmente se dará una relación entre la responsabilidad del Estado al implementar la interdicción como una garantía y las afecciones que de esta figuran nacen, sin tener un balance entre lo que comprende una protección y la desigualdad que esta puede generar a su vez.

Lo anterior implica encarar el siguiente interrogante: ${ }_{i}$ Es posible que se configure un vicio de procedimiento en actos jurídicos ejercidos desde la actuación del litigio por parte de un profesional del derecho con síndrome de Down si no se hace un estudio previo de su coeficiente intelectual?

Este capítulo se desarrolla mediante una metodología descriptiva y analítica, a partir de la cual se evalúa cada uno de los aspectos que llevan a la violación de derechos cuando una persona es declarada interdicta por tener síndrome de Down y, por ende, se conciben limitaciones en cuanto a su ejercicio profesional del derecho. Este estudio está respaldado por una investigación analítica de leyes, jurisprudencia y doctrina que, de una u otra forma, hacen referencia a casos semejantes.

\section{La interdicción en Colombia}

La interdicción es el medio por el cual se busca declarar a una persona impedida para realizar ciertos actos jurídicos, desde negocios hasta la toma de 
sus propias decisiones, ya sea por alguna afección mental, inmadurez psicológica, discapacidad intelectual o cognitiva, entre otros.

A su turno, hay dos clases de incapaces generales: incapaces absolutos e incapaces relativos. Mientras los primeros no tienen aptitud para realizar prácticamente ningún acto voluntario con connotación jurídica y los que eventualmente realicen se consideran absolutamente nulos, los segundos poseen un limitado campo de acción jurídica y sus actos se toman como relativamente nulos. (Medina-Pabón et al., 2009, p. 12)

Esto configura una discapacidad o limitación a los derechos de estas personas y da lugar a que el Estado dé un trato especial a las actuaciones jurídicas de los interdictos, ya que a estos se les nombra a una persona encargada de la administración de sus bienes, con el fundamento siguiente:

La protección de los más débiles constituye en general no solo un deber en algunos individuos, sino un deber social. La razón fundamental de las figuras tuitivas se encuentra en un deber de asistencia y protección que tiene su origen en la debilidad e imperfección del ser humano. Así bien, proponemos no caer en el error de olvidarse de aquellos sujetos que por sus especiales circunstancias de vulnerabilidad no pueden acceder al goce y ejercicio de sus derechos y necesitan, por ello, de un determinado cuidado y protección tanto de su persona como se sus bienes. (Cazorla González-Serrano, 2010, p. 48)

De esta forma, la Constitución Política de Colombia contempla en su artículo 47: "El Estado adelantará una política de previsión, rehabilitación e integración social para los disminuidos físicos, sensoriales y psíquicos, a quienes se prestará la atención especializada que requieran" (Constitución Política de Colombia, 1991, art. 47). Es necesario conocer que, detrás de esto, hay toda una estructura que se contempla desde el derecho romano hasta nuestros tiempos.

De hecho, la privación de los derechos o muerte civil —llamada actualmente interdicción - tiene antecedentes en el derecho romano, cuyo nombre en latín es capitis deminutio (capacidad disminuida), que hace referencia a la incapacidad jurídica de obrar de una persona, es decir, a una incapacidad para el ejercicio cabal de los derechos civiles por parte de un individuo. Históricamente, esta privación de los derechos civiles y jurídicos se ha presentado en formas y situaciones diferentes: la máxima capitis deminutio, por 
ejemplo, se da cuando a una persona le es arrebatada de forma absoluta su libertad y ciudadanía (Arroyave, 2018, p. 24).

En particular, para una especial protección de los derechos de las personas declaradas interdictas, se creó la figura de las guardas para aquellos que no estaban bajo patria potestad. Así, es posible detallar que lo originado en el derecho romano se mantuvo en el Código Civil de Napoleón de 1804 y se acogió por el Código Civil de Bello, que entró en vigencia en la República de Chile en 1853. Este último fue adoptado por el ordenamiento civil colombiano en 1873, régimen de tutelas y curatelas que estuvo vigente en Colombia hasta el 5 de junio de 2009.

En Roma, por su parte, se sabía que el paterfamilias ${ }^{6}$ que tuviere a su cargo una persona que se encontrase en un estado de incapacidad para actuar debía ejercer actos en nombre de esta y sería responsable de su cuidado. Así, en la actualidad, esta insuficiencia a la que se refiere el ítem anterior se debe a la falta de capacidad de ejercicio, como lo exponen Enamorado et al::

la capacidad de ejercicio está supeditada a una cierta madurez para que su titular pueda ejercer por sí mismo sus derechos y a la vez contraer obligaciones, y aquellas personas que no tienen o carecen de esa madurez solo puedan ejercerla por medio de un representante. (p. 32)

De manera análoga — con el fin de hacer referencia a la capacidad y su evolución histórica_-, el Código de Napoleón no usaba la expresión patria potestad, como se hacía en las leyes de interdicción de Roma, puesto que el primero utilizaba "el poder del padre para regular los derechos y deberes entre padres e hijos, [...] hablaba de la autoridad parental, que era conferida también a la madre, salvo que mientras subsistiera el matrimonio era ejercida exclusivamente por el padre” (Rodríguez, 2010, \$7).

En consecuencia, el Código de Napoleón dispuso:

La interdicción civil y el consejo judicial; que se refería a los discapacitados mentales y empleaba adjetivos que en su momento constituyeron la fisiología médica y psiquiátrica de la época, consagrados en los artículos 489 como: el

6 "El paterfamilias es la figura central al interior del esquema familiar roma. Como hemos visto, las relaciones de parentesco agnaticias se estructuran entorno a él, determinando la sujeción al pater la pertenencia a la familia proprio iure" (Amunátegui-Perell, 2006). 
mayor de edad que esté en un estado habitual de imbecilidad, de demencia o de furor debe ser sujeto a interdicción, aun cuando ese estado presente intervalos lúcidos. (Tirado \& García, 2018, p.158)

Esto mismo está contemplado en el artículo 545 de la Ley 57 de 1887 de Colombia (Código Civil anterior), al referirse a que la persona que se encuentre en estado de demencia deberá ser privada de la administración de sus bienes, por esta razón la Ley 1309 de 2009 de Colombia afirma

Los actos realizados por la persona con discapacidad mental absoluta, interdicta, son absolutamente nulos, aunque se alegue haberse ejecutado o celebrado en un intervalo lúcido y los realizados por la persona con discapacidad mental relativa inhabilitada, en aquellos campos sobre los cuales recae la inhabilitación son relativamente nulos. (art. 44)

Las normas anteriormente mencionadas son una breve recopilación de la protección que ha dado el ordenamiento jurídico al patrimonio y actuaciones jurídicas que tengan relación con las personas declaradas interdictas. Esto supone no solo un desequilibrio en la igualdad que existe entre las personas que gozan libremente de todos sus derechos y aquellas que por alguna discapacidad física o mental no se encuentran en el pleno goce y disfrute de estos, sino que, a su vez, demuestra cómo no a todos los miembros del Estado colombiano se les trata como personas que son sujetos de derechos, con igualdad de ejercicio y condiciones sobre estos (Bermúdez-Tapia, 2017).

\section{La interdicción como acto de discriminación entre iguales $y$ desiguales}

En vista de lo anterior, se han creado medidas internacionales por medio de algunos pactos, convenciones ${ }^{7}$ y declaraciones, entre otras, que han dado

7 La Convención sobre los Derechos de las Personas con Discapacidad (2006) reconoce el derecho de las personas con discapacidad a la educación sin discriminación y sobre la base de la igualdad de oportunidades. Para la realización de dicho derecho se requiere que los Estados partes aseguren un sistema de educación inclusivo a todos los niveles, así como la enseńanza a lo largo de la vida, desarrollando plenamente el potencial humano y el sentido de la dignidad y la autoestima, para permitir así el máximo desarrollo de la personalidad, los talentos y la creatividad de las personas con discapacidad, haciendo posible su participación de manera efectiva en una sociedad inclusiva. 
lugar a otorgarles las condiciones de capacidad absoluta sobre los derechos a las personas que se encuentran impedidas de estos. La creación de las Normas Uniformes sobre la igualdad de oportunidades para las personas con discapacidad tienen la finalidad de garantizar que estas,

en su calidad de miembros de las respectivas sociedades, puedan tener los mismos derechos y obligaciones que los demás. En todas las sociedades del mundo hay todavía obstáculos que impiden que las personas con discapacidad ejerzan sus derechos y libertades y dificultan su plena participación en las actividades de sus respectivas sociedades ${ }^{8}$. Es responsabilidad de los Estados adoptar medidas adecuadas para eliminar esos obstáculos. Las personas con discapacidad y las organizaciones que las representan deben desempeñar una función activa como copartícipes en ese proceso. (Naciones Unidas, 1994, p. 7.)

Normas como la anterior han creado una nueva noción sobre la discapacidad de los interdictos, valoración con la que se quiere llegar a precisar si algunas condiciones de su capacidad mental o física no encajarían con los preceptos sociales que se necesitan para llevar una vida "normal”. En otras palabras, tener un aprendizaje diferente o que sea incluso lento a diferencia de las demás personas configura en sí que no se tenga la capacidad para obrar en ciertos actos jurídicos, lo que se respondería acertadamente, dada la falta de legitimidad que tienen las personas llamadas interdictas por el Estado colombiano.

De esta manera, y en relación con la convención, Sosa (2019) afirma que la discapacidad debe ser entendida como una forma de construir al otro distinto a nosotros en términos de igualdad, siendo críticos en el análisis en la comparación entre normales y anormales, sin que importe la medida de la anormalidad, en donde se dé por hecho que no existen personas normales y discapacitadas y que la discapacidad pueda ser vista como una simple alteración física o mental de las personas.

De acuerdo con lo anterior, hacia fines de la década de los sesenta, las organizaciones de personas con discapacidad que funcionaban en algunos

8 "El reconocimiento y exaltación de los derechos humanos como factores supremos hace que se consolide un nuevo orden extraterritorial, en el que los tratados, convenciones y pactos forman un cuerpo normativo universal, que no limita a una jurisdicción o competencia determinada, sino que opera en el marco de una competencia y jurisdicción única, universal y trasnacional" (Martínez-Lazcano et al., 2014, p. 122). 
países empezaron a formular un nuevo concepto de esta. En él se reflejaba la estrecha relación existente entre las limitaciones que experimentaban esas personas, el diseño y la estructura de su entorno y la actitud de la población en general (Naciones Unidas, 1994, p. 4).

A manera de ilustración de esto, es importante reconocer que se vive a diario en un sistema totalmente complejo, en un régimen que es íntegramente discriminatorio, que está sujeto a condiciones socioculturales y políticas que no permiten que personas con una limitación ingresen al sistema, incluso si se trata de una afección que no pondría en riesgo el actuar de la persona que la sufre ni de la sociedad en general.

Es preciso, entonces, matizar el concepto de discriminación; ¡es discriminación exigir a los individuos miopes gafas para conducir? [...] la diferencia entre la "discriminación odiosa", frente a la que procede el amparo, y la "discriminación razonable", esto es, tratar razonablemente en forma desigual a los desiguales [...] el problema radica en apreciar si una discriminación es "razonable". Destacan que este carácter razonable de la discriminación ha de ser probado por aquel que la estableció, o lo que es lo mismo, corresponde probar que una discriminación es razonable a quien en un acto general o particular establece una discriminación. Esta se debe mostrar como fundada y razonable, de acuerdo con criterios y juicios de valor generalmente aceptados. (GarcíaCuevas, 2015, p. 247)

Entendida así, la discriminación abre un abanico de posibilidades desde el cual se deben valorar otros preceptos, como la igualdad.

Quienes entienden el principio jurídico de la igualdad como generalidad expresan que la ley debe tratar a las personas según "géneros"; La generalidad alude a categorías de iguales y desiguales atendido un determinado régimen de disparidad. Así con respecto a la igualdad ante la ley podemos señalar que la igualdad que reclama la garantía en comento, se traduce en generalidad, esto es, agrupar a las personas en géneros acorde con factores de discriminación rectamente empleados. (Valdés, 1992, p. 37)

En otro sentido, es necesario entender la igualdad relativa contrapuesta a una igualdad absoluta. Se presupone que

[...] la igualdad ante la ley consiste en que las normas jurídicas deben ser iguales para todas las personas que se encuentren en las mismas circunstancias 
fácticas y que no se trata, por consiguiente de una igualdad absoluta, sino que debe aplicarse la ley [...] en cada caso conforme a las diferencias específicas. La igualdad de la que venimos hablando exige la distinción razonable entre quienes no se encuentran en la misma condición, por lo que ella no impide que la legislación contemple en forma distinta situaciones diferentes, siempre que la discriminación no sea arbitraria ni responda a un propósito de hostilidad contra determinadas personas o grupos de personas, o importe indebido favor o privilegio personal o de grupo. (Cabrera, 2004, p. 12)

Aclarado lo anterior, es posible revisar una de las grandes problemáticas $\mathrm{y}$ violaciones que emanan de todo lo visto anteriormente y que afectan a las personas con síndrome de Down. Estas últimas son declaradas interdictas, con lo cual se da paso a la violación de sus derechos fundamentales, pero este artículo se centra en uno en especial: la vulneración del derecho al acceso de la educación superior y al ejercicio del litigio en una carrera como el derecho.

\section{Generalidades sobre el síndrome de Down}

La discusión que se presenta frente a las personas que son interdictas por tener síndrome de Down coexiste en el estudio que se debe tener en cuenta en cada individuo, pues la ley no se debe interpretar como una regla genérica, sino que se debe estudiar para cada caso en particular, como el cuadro clínico de cada paciente con síndrome de Down. Entendido esto, se desarrollan las diferentes particularidades de esta patología. El síndrome de Down consiste en un "trastorno genético causado por la presencia de una copia extra del cromosoma 21, en vez de dos habituales, caracterizado por la presencia de un grado variable de retraso mental y unos rasgos físicos peculiares que le dan un aspecto reconocible" (Basile, 2008, p. 9).

Estos niños van a tener un desarrollo más lento, sus características y ritmos de aprendizaje serán a menudo diferentes en determinados aspectos (memoria, atención, lenguaje...) así se detectó que estos niños suelen tener dificultades a la hora de La integración e inclusión escolar de los niños con Síndrome de Down mantener la atención en periodos de tiempo prolongados y facilidad para la distracción ante estímulos novedosos. Sin embargo, su desarrollo en otros aspectos está ligado a su edad cronológica (curiosidades, intereses, necesidades...) por lo que no deben ser comparados con niños más jóvenes, aunque 
sus edades mentales, medidas a través de test estandarizados, sean equivalentes. (Rodríguez, 2013, p. 15)

Lo anterior equivale a entender que cada caso es único, que estudiar la validez de un acto jurídico de una persona con síndrome de Down corresponde a una ardua observación de las diferentes capacidades que esta persona ha desarrollado a lo largo de su vida. Es por esto que si la interdicción pretende una garantía para la protección de la igualdad de los derechos de estas personas —interdicción que generalmente se desarrolla en el ámbito familiar (Bermúdez-Tapia, 2014)_, se le deben garantizar no como si todos representaran una comunidad que ha avanzado dentro de los mismos parámetros o, mejor aún, dentro del mismo grado de conocimiento, pues esto es contrario al proceso que en realidad estas personas llevan.

Por otro lado, es importante saber que no "existe tratamiento para el síndrome de Down, sin embargo, se realizan una serie de medidas de carácter rehabilitador, que les permita una inserción a la sociedad, introduciéndolos a la individualidad y autocuidado, ofreciendo consiguientemente una mejor calidad de vida" (Pérez Chávez, 2014, p. 2). En consecuencia, el marco jurídico se debe convertir en una gran extensión de garantías y oportunidades, pues cabe aclarar que a estas personas se les vulnera en gran parte todos sus derechos al no tener el pleno disfrute de su capacidad de ejercicio y de goce?

Por tanto, la interdicción y otras limitaciones a la capacidad jurídica de las personas con discapacidad intelectual o mental que se encuentran presentes en el ordenamiento jurídico ponen en tela de juicio la aplicabilidad del principio de igualdad y no discriminación arbitraria al confundir la capacidad jurídica con la capacidad mental. Es de esta forma como se vulneran derechos tan importantes como el derecho a la autonomía, el derecho a la vida privada, el derecho a la rehabilitación y el derecho a la libertad, entre otros, situación que urge remediar a través del reemplazo del sistema de susti-

9 La capacidad jurídica ha sido definida tradicionalmente por el derecho decimonónico como el resultado de dos ámbitos de la capacidad, de goce y de ejercicio: "la capacidad de goce es la aptitud jurídica para adquirir derechos y contraer obligaciones. La capacidad de ejercicio o legal es la habilidad de la persona para poderse obligar por sí misma, sin la intervención o autorización de otra” (Ley 57 de 1887, Congreso de la República, Codio Civil, art. 1502). 
tución o invalidación de la voluntad por un sistema de apoyos y salvaguardas (González, 2018, p. 105).

A lo anterior se añade la vulneración del derecho a la educación superior $^{10}$ y al trabajo que se deriva de esta. Tal situación, en consonancia con el quebrantamiento de los derechos fundamentales, implica buscar una respuesta frente a por qué las personas con síndrome de Down son aisladas de los derechos que les son inherentes. Una de las múltiples respuestas tiene que ver con los siguientes aspectos:

Aunque la política y reglamentación educativas para las personas con discapacidad en Colombia, han sido objeto de interés de diferentes actores políticos y de la sociedad civil por más de una década al presente, éstas se han restringido a los lineamientos para la educación básica primaria y secundaria, y no se han hecho extensibles al nivel superior. (Mejía Díaz, 2003)

Se ha olvidado que la esencia de acceder a este nivel de educación, es tener la oportunidad de desarrollar habilidades sociales, aumentar los conocimientos y cualificarse para ingresar al mundo laboral, y contribuir así de una forma importante al desarrollo e inclusión en la sociedad. (Parra, 2003)

Hay que mencionar además que [...] no todas las personas con síndrome Down tendrán los mismos síntomas ni los presentarán siempre en la misma intensidad [...]. La consecuencia jurídica de esta realidad es que no será fácil en todos los casos aplicar una categoría genérica que otorgue un marco jurídico aplicable a una persona con síndrome Down. (Cruces Burga, 2015, p. 70)

Lo anterior no quiere decir que el Estado se libre de dicha responsabilidad solo porque este síndrome tiene un amplio campo de estudio, sino que, por el contrario, tendrá que ponderar en igualdad de condiciones las garantías a todo ciudadano que sea sujeto de derechos, y esto incluirá analizar en qué clasificación caben las personas con síndrome de Down que por su retraso mental o deficiencia intelectual no podrían discernir o entender campos de estudio como el derecho. De esta manera, no se daría por sentado que todos los individuos que padecen este síndrome tienen la misma deficiencia cognitiva.

10 Como política de protección estatal, deben eliminarse las barreras educativas que afectan a este sector de la población. Las personas discapacitadas o minusválidas que desean cursar estudios deben recibir el mismo trato que el resto de estudiantes (Mejía Díaz, 2007, p. 35). 


\section{Capacidad cognitiva y capacidad de discernimiento}

En consecuencia, será de mayor ayuda tener en claro algunos conceptos abarcados en el apartado anterior:

El retraso mental se refiere a limitaciones sustanciales en el funcionamiento actual. Se caracteriza por un funcionamiento intelectual significativamente inferior a la media, que generalmente coexiste junto a limitaciones en dos o más de las siguientes áreas de habilidades de adaptación aplicadas: comunicación, autocuidado, vida en el hogar, habilidades sociales, utilización de los servicios de la comunidad, autodirección, salud y seguridad, rendimiento académico funcional, tiempo libre y trabajo. El retraso mental se ha de manifestar antes de los 18 años de edad ${ }^{11}$. La determinación objetiva del "funcionamiento intelectual significativamente inferior a la media" nos obliga a realizar una valoración de la capacidad intelectual mediante la aplicación de pruebas o test de inteligencia administrados individualmente y teniendo en cuenta las características peculiares de la persona que se está evaluando. (Ruiz, 2001, p. 7)

Conviene subrayar que, aunque el retraso mental se manifieste antes de los 18 años, el conocimiento intelectual del individuo no necesariamente queda truncado (Calero, 2006). Lo cierto es que jamás se podrán comparar dos niños con la misma edad, ni siquiera uno con síndrome de Down y otro completamente sano en cuanto a su capacidad intelectual, pues el desarrollo de estos se produce en un tiempo y en una forma distinta. De esta forma, a su manera, las personas con síndrome de Down pueden mostrar a cierta edad su capacidad de obrar con sensatez y madurez; lo que difiera en esta etapa de madurez será que tal vez esta no venga acompañada de la experiencia de hábitos que son aparentemente imprescindibles. Además, no se le puede pedir un mismo entendimiento para determinado tema a una persona a la cual se le ha enseñado y se le han puesto en práctica dichas enseńanzas que a una persona que toda su vida ha estado bajo un concepto de no poder ejercer ciertos actos.

11 El coeficiente intelectual de los adultos es bastante estable, aunque durante la infancia varía notablemente, comenzando a estabilizarse hacia los 11-12 años. La educación y la práctica de los test ayudan a mejorar las puntuaciones de estos y, por lo tanto, "mejoran" el coeficiente intelectual. Los programas de "educación compensatoria" y los de "modificabilidad de la inteligencia", como el Proyecto Inteligencia de Harvard o el Programa de Enriquecimiento Instrumental de Feuerstein, entre otros, se basan en estas premisas (Yuste, 1994). 
Por otro lado es necesario considerar al adolescente con síndrome de Down como un individuo necesitado de una interacción social,

pues es preciso introducir la formación en el conocimiento de las propias emociones y el dominio suficiente de las mismas para lograr llevar a la persona con síndrome de Down hacia su proyecto vital individual, una mayor autosatisfacción personal, una ampliación de sus interacciones sociales o un más alto grado de autocontrol. (Ruiz et al., 2009, p. 126)

Así, podemos entender que "se propone un nivel más dinámico y funcional, donde además del funcionamiento cognitivo deficitario, adquieren gran importancia las habilidades adaptativas aplicadas que se basan en la imprescindible interacción entre tres elementos: capacidades, ambientes y apoyos" (Rincón Bustos, 2009, p. 9).

En contraste con lo anterior, es necesario tener en cuenta otro punto para la valoración de la interdicción:

Rabinovich-Berkman habla del discernimiento como la aptitud de entender la licitud o ilicitud del acto y con la habilidad de conocer y comprender. También señala que "el discernimiento importa la aptitud de abstraer, de formular conceptos eidéticos (ideas)", y agrega: Sujetos con síndromes de Down poco acentuados, o padeciendo debilidad mental no severa, pueden perfectamente elaborar abstracciones a partir de los textos normativos y comprender si sus conductas proyectadas se adecuan o no a ellas. (Llorens, 2007, p. 10)

Estimar entonces que el simple hecho de tener síndrome de Down comporta una clara deficiencia del intelecto, el raciocinio o la lucidez es una nítida ejemplificación de cómo se sobreponen otros aspectos que son irrelevantes y no los verdaderamente importantes, para declarar a una persona impedida para el estudio y ejercicio de la carrera de derecho o incluso de cualquier otra.

Por otro lado se debe Trabajar a favor de la autodeterminación que implica fundamentalmente un cambio de perspectiva. Supone considerar a las personas con discapacidad como capaces de participar en el desarrollo de su propia vida, y verlas como sujetos con derechos, talentos, habilidades, fortalezas y necesidades de apoyos. Nos exige, además, dejar de pensar en programas a los que las personas con discapacidad tienen que adaptarse y preguntarles por lo que ellas quieren. En definitiva, sustituir el control externo y experto, que lleva 
a la dependencia, por la capacitación de la persona, que lleva a la autodeterminación. (Torres et al., 2013, p. 16)

Esta autodeterminación de la que se habla en el texto citado hace referencia a las consecuencias que trae consigo la interdicción, pues como lo mencionan Palací y Moriano (2013, p. 77) en muchas personas con discapacidad se ha arraigado cierta cultura de la pasividad, inspirada por las circunstancias ambientales, que inducen a muchos discapacitados a pensar que carecen de potencialidades laborales y que, por tanto, han de depender económicamente de las políticas asistenciales o de las familias.

Entonces, de cualquier modo no es solo el Estado el que tiene una responsabilidad intrínseca con las personas discapacitadas, sino también la comunidad en general, puesto que "las interacciones de los miembros de la sociedad con las personas con discapacidad intelectual muchas veces son las que limitan la autonomía y el autoconcepto de estas personas" (Díaz, 2010, p. 115). Por este y otros puntos se habla de una educación que debe aplicarse a una sociedad para convivir y saber comprender lo que las personas con síndrome de Down e incluso con alguna otra discapacidad pueden aportar para la comunidad y, por tanto, requieren gozar de igualdad de derechos para beneficio común.

\section{El acceso a la educación superior}

Este apartado tiene como finalidad dar a entender que en los ámbitos social, económico o laboral "es más humano, más socialmente digno y más rentable económicamente que las personas con discapacidad desempeñen un rol activo y productivo, en lugar de continuar en una posición pasiva y dependiente" (Palací \& Moriano, 2003, p. 72).

En este orden de ideas, la interdicción es la secuela de las dilaciones que viven a diario las personas con síndrome de Down al momento de querer ejercer sus derechos. Esto es así porque, aunque hay millones de leyes establecidas en pro de los derechos de las personas discapacitadas, pareciera que estas estuviesen siempre acompañadas de alguna barrera, como la interdicción y la no materialización de la inserción en la educación superior. Como lo mencionan Echeita y Ainscow (2011), la inclusión precisa la identificación y 
la eliminación de barreras. El concepto de barreras es nuclear a la perspectiva en revisión, puesto que son las barreras las que impiden el ejercicio efectivo de los derechos, en este caso, a una educación inclusiva.

Genéricamente, debemos entender como barreras aquellas creencias y actitudes que las personas tienen respecto a este proceso y que se concretan en las culturas, las políticas y las prácticas escolares se sostienen individual y colectivamente. Cuando tales barreras interactúan con las condiciones personales, sociales o culturales de determinados alumnos o grupos de alumnos —en el marco de las políticas y los recursos educativos existentes a nivel local, regional o nacional-, generan exclusión, marginación o fracaso escolar (Echeita \& Ainscow, 2011).

Lo anterior tiene que ver con la exclusión de estos individuos de la educación superior, a pesar de ser uno de los derechos fundamentales consignados en la Constitución Política y en importantes convenios internacionales —según estos, amparada y en prevalencia sin importar las condiciones físicas, de sexo, intelectuales o de cualquier otra índole—. De acuerdo con esto, Molina et al. refieren que

el sistema educativo, y esencialmente la universidad, comparten la responsabilidad en el proceso de construcción y atribución de significados que los futuros maestros realizan ante los diferentes escenarios que perciben. En concreto, orientar la percepción de las diferentes capacidades (y no solo las mal llamadas discapacidades), es una tarea esencial de la universidad que debe completarse, precisamente, con la propia aportación de la opinión y experiencia de las personas. (2012, p. 13)

En relación con todo lo dicho anteriormente, se asegura que todos los actos ejercidos desde el litigio por una persona con síndrome de Down configuran un vicio, una tacha que responde a un modelo educativo, social y político que se ha impuesto en el marco jurídico. Esto corresponde a la aprobación del trato de derechos de los discapacitados no como garantías sino como ofertas que el mercado ofrece, y que serán válidas solo para quienes cuenten con un historial apropiado. Esto concuerda con que "el reconocimiento de la diversidad parte del principio de inclusión educativa" (Sevilla Santo et al., 2017, p. 85). La interdicción, entonces, no se puede entender como un mecanismo alterno del 
conflicto, sino que entorpece, con sus distintas limitaciones, a un Estado que quiere pero no ha podido dar solución de continuidad a las garantías que por décadas ha tratado de establecer para las personas con síndrome de Down. En efecto, Melgarejo (2018) expone que la educación superior con calidad como un derecho fundamental a favor de las personas con discapacidad es un tema objeto de discusión en el Estado colombiano, el cual ha venido adoptando una política inclusiva tan solo aparente, que no cumple ni siquiera con un mínimo de posibilidades para quienes quieren ejercer una carrera, dentro de un marco de vida que les genera más obstáculos que salidas.

\section{La violación del derecho al litigio de las personas con síndrome de Down}

Este apartado se desarrolla en torno al tema de la inclusión de personas con síndrome de Down en el mercado laboral colombiano, en especial, aquellas que aspiran a ejercer una carrera como abogados. Se aborda, así, la violación de derechos fundamentales producto de la interdicción, como la vocación, el trabajo y la educación.

Para entender por qué son violados estos derechos al momento de hablar de interdicción y del vicio procesal que de esta se desprende en los actos ejercidos por personas con síndrome de Down en el ejercicio de la abogacía, es importante recordar lo expuesto por Ordóńez:

La vocación profesional es un proyecto de intenciones y aspiraciones que desea alcanzar una persona, al inclinarse, prepararse y formarse con deseos de superación, para el ejercicio de una profesión, con espíritu de servicio, tomando en cuenta lo que conoce, lo que piensa y desea hasta lograr los objetivos y metas trazadas [...] es el resultado de combinar nuestras aptitudes y potencialidades con los valores éticos y jurídicos que desea la comunidad. (2012, pp. 15-16)

En este sentido, es menester tener en cuenta que no se trata solo de los sueños de las personas, sino de su materialización, mediante el recurso de un título que los haga posibles gracias al ejercicio de una carrera libremente elegida. El verdadero problema surge en la medida en que se ha creado una inmensa acumulación de leyes y de acuerdos que buscan precisamente alcanzar el gran 
objetivo de dar igualdad de oportunidades en todos los aspectos a las personas, pero su ejecución es un problema, como lo expresan Palací y Moriano:

Se ha conseguido el respaldo de la comunidad internacional para la sensibilización de los gobiernos y de los agentes sociales en relación con las obligaciones que se deben asumir para atender a sus ciudadanos con discapacidad. Llevamos décadas trabajando sobre los mínimos que deben cumplirse en esta materia, elaborando normas de carácter multilateral, cartas sociales, códigos de conducta, legislación específica, programas de toda índole, sin que la realidad cambie con la intensidad requerida por el problema. Hemos asumido, en tanto que comunidad mundial, valores que ya están incorporados a nuestras normas y reglas, pero no siempre a nuestros esquemas mentales y a nuestras conductas. (2013, p. 12)

Ahora bien, "a partir del siglo XIX la abogacía alcanzo jerarquía de profesión liberal, cuyo ejercicio podían realizar solamente las personas que tuvieran conocimientos y prácticas suficientes como para garantizar, de alguna manera, los trabajos confiados a ellos" (Ushca Ushca, 2014), entonces, se infiere que el problema regresa siempre al mismo punto, ya que la ley da por hecho que todos los actos jurídicos del litigio ejercidos por una persona con síndrome de Down estarán bajo un vicio de procedimiento. En efecto, se juzga a la persona con este síndrome que quiere ejercer, sin antes haber estudiado el conocimiento que ostenta, su formación y las capacidades con que cuenta para litigar.

Se puede afirmar, por tanto, que más que un problema normativo es un problema social de inclusión verdadera: "lejos de orientarse al desarrollo de la inteligencia del estudiante y de la racionalidad de sus facultades, [...] responde más bien a exigencias de facilidad y utilidad y, en definitiva, a demandas de mercados" (Del Rey \& Sánchez-Parga, 2011).

En dicho sentido, se habla de unas garantías mínimas, un aval que dé lugar no a un amparo por medio de la interdicción - cuya única función es entorpecer el derecho de igualdad-, sino que responda a un verdadero interés de las partes, a un estudio de las personas con vocación de litigar. Como se menciona en el proyecto Tuning ${ }^{12}$,

12 Tuning es "una red de comunidades de académicos y estudiantes interconectadas, que reflexiona, debate, elabora instrumentos y comparte resultados. Son expertos, reunidos alrededor de una disciplina y con el espíritu de la confianza mutua. Trabajan en grupos internacionales e interculturales, siendo totalmente respetuosos de la autonomía a nivel institucional, nacional y regional, intercambiando 
no se puede reducir al simple desempeńo laboral, tampoco a la sola apropiación de conocimientos para saber hacer, sino que abarca todo un conjunto de capacidades, que se desarrollan a través de procesos que conducen a la persona responsable a ser competente para realizar múltiples acciones (sociales, cognitivas, culturales, afectivas, laborales, productivas), por las cuales proyecta y evidencia su capacidad de resolver un problema dado, dentro de un contexto específico y cambiante. (Clavijo et al. 2002, p. 188)

Lo anterior hace referencia a una búsqueda infinita de mecanismos que solventen precisamente el problema de la creación de barreras, pero a estas se suman leyes inconcretas, leyes que no van al margen de lo que se impone, pero que se pregonan de forma muy distinta en la carta política colombiana. Uno de los ejemplos más cercanos es la Ley 1905 (2018), "Por la cual se dictan disposiciones relacionadas con el ejercicio de la profesión de abogado”, en la que se expresa claramente que

para ejercer la profesión de abogado, además de los requisitos exigidos en las normas legales vigentes, el graduado deberá acreditar certificación de aprobación del Examen de Estado que para el efecto realice el Consejo Superior de la Judicatura (CSJ), directamente o a través de una Institución de Educación Superior acreditada en Alta Calidad que se contrate para tal fin.'. Se entenderá aprobado el Examen de Estado cuando el resultado supere la media del puntaje nacional de la respectiva prueba. En el resultado individual de cada examen, el CSJ señalará la representación porcentual del puntaje obtenido sobre la media nacional. (art. 1)

Este artículo es una muestra más de las inconsistencias legales, pues serán nulos por vicio procedimental los actos ejercidos desde el litigio por una persona solo por tener síndrome de Down. Esto quiere decir que no se tendrá en cuenta ni siquiera el examen que le permitiría ejercer actos de abogado si este en algún momento tuviera la oportunidad de presentarlo, y aun si fuera aprobado, no tendría validez, por cuanto fue realizado por un interdicto con síndrome de Down. Del mismo modo se introduce en Consúltele al Experto, al exponer que

conocimientos y experiencias. Desarrollan un lenguaje común para comprender los problemas de la educación superior y participan en la elaboración de un conjunto de herramientas que son útiles para su trabajo y que han sido pensadas y producidas por otros académicos" (Villa, 2013). 
La interdicción es una figura sustitutiva de la voluntad, a través de la cual se sustrae la capacidad jurídica de la persona sujeta a trámite, por medio de una declaración judicial. En otras palabras, cuando una persona es sometida a la interdicción, se anula su posibilidad de tomar decisiones con efectos jurídicos, y será un tercero el que decida y tome las riendas de la vida de la persona con discapacidad. Así las cosas, bajo medida de interdicción la persona no puede decidir por sí misma ni siquiera sobre asuntos personalísimos como dónde y con quién vivir, contraer matrimonio, celebrar contrato laboral, manejar dinero, qué estudiar, etc. La interdicción, contrario a lo que se ha creído, no es una gura que proteja a la persona pero sí la anula en el mundo jurídico. Por ello, la Convención de las Naciones Unidas sobre Derechos de las Personas con Discapacidad establece que este tipo de figuras debe desaparecer, en cuanto representan una vulneración directa a la posibilidad de contraer obligaciones y ejercer ciertos derechos. Por eso, debe evitarse a toda costa someter a interdicción a una persona con discapacidad, y en su lugar se deben proveer todos los medios posibles para prestar apoyo y efectuar ajustes que permitan que la persona transmita su voluntad y sus preferencias. Bajo este modelo se fomenta que la persona con discapacidad sea titular de derechos y se vea respaldada — no sustituida—, en su proceso de toma de decisiones. (2016, p. 18)

En cierto modo, lo anterior es la consecuencia de un sistema que se ha encargado de establecer una garantía para las personas con síndrome de Down llamada interdicción, que es solo la consecuencia de la violación de múltiples derechos, por cuanto no cumple una función de mediación para prestar un aval de derechos, como lo respalda la Ley 1618 de 2013:

El Ministerio de Justicia y del Derecho, o quien haga sus veces, en alianza con el Ministerio Público y las comisarías de familia y el ICBF, deberán proponer e implementar ajustes y reformas al sistema de interdicción judicial de manera que se desarrolle un sistema que favorezca el ejercicio de la capacidad jurídica y la toma de decisiones con apoyo de las personas con discapacidad, conforme al artículo 12 de la Convención sobre los Derechos de las Personas con Discapacidad de Naciones Unidas. (art. 21, núm. 2)

En este punto, en el que se ha afianzado la importancia de incluir no solo leyes y normas que traten de amparar los derechos de las personas con síndrome de Down, sino la materialización de estas, se recalca la necesidad de educación para una sociedad que entienda que

no existen personas discapacitadas sino personas con 'capacidades distintas', por lo que la sociedad debe evolucionar hacia una sociedad 'más plural', donde 
las personas con síndrome de Down no sean tratadas como niños y donde se fomenten sus capacidades e independencia desde temprana edad. ("No somos personas con discapacidad, sino con capacidades y habilidades diferentes", 2017)

Se destaca de la cita anterior que uno de los entrevistados es un español diagnosticado con síndrome de Down, quien fue el primer europeo con esta cualidad en recibirse de una carrera universitaria; en verdad, a estas alturas, con

un Diplomado en Magisterio, y a punto de terminar los estudios de Psicopedagogía en la Universidad de Málaga, Pablo Pineda se siente orgulloso de ser una persona con Síndrome de Down que puede demostrar que su desarrollo es producto del entorno cultural y social, más que de los determinantes biológicos. Y, al mismo tiempo, lamenta los tópicos que persisten en torno a estas personas: desde un proteccionismo "enmascarado", a las dificultades para independizarse o la invasión de su intimidad. (Del Águila et al., 2010, p. 40)

Y lo hizo en igualdad de condiciones que sus colegas, sin ninguna adaptación especial, toda una hazaña para alguien con esa condición genética en un mundo tremendamente discriminador.

\section{Referencias}

Amunátegui-Perell, C. F. (2006). El origen de los poderes del Paterfamilias. Revista de Estudios Histórico-Jurídicos, 28, 37-143. http://dx.doi.org/10.4067/S0716-54552006000100002

Arroyave, M. (2018). La demencia como objeto judicial en Antioquia entre 1886 y 1936 [Tesis de pregrado, Universidad de Antioquia]. DocPlayer. https://docplayer.es/153801887-La-demencia-como-objeto-judicial-en-antioquia-la-interdiccion-entre-1886-y-1936-alejandro-arroyave-moreno.html

Basile, H. (2008). Retraso mental y genética Síndrome de Down. Revista Argentina de Clínica Neuropsiquiátrica, 15(1), 9-23.

Borea, C. (2015). Discapacidad y derechos humanos. Thēmis - Revista de Derecho, 67, 167-175. http://revistas.pucp.edu.pe/index.php/themis/article/view/14465

Cabrera, M. (2004). El derecho a la igualdad ante la ley y la interdicción de la arbitrariedad administrativa [Tesis doctoral, Universidad Austral de Chile]. Cybertesis.

Calero, C. M. (2006). La integración jurídica y patrimonial de las personas con discapacidad psíquica o intelectual. Editorial Universitaria Ramón Areces.

Cazorla González-Serrano, M. C. (2010). La protección jurídico-patrimonial del menor y del incapacitado y su antecedente histórico en Derecho Romano. Revista de Derecho de la UNED, 7, 121-168. 
Clavijo, N., Pinilla, A., \& Sánchez, J. (Eds.). (2002). Reflexiones en educación universitaria. Universidad Nacional de Colombia.

Consúltele al Experto. (2016). Derechos de las personas con discapacidad, Ministerio de Justicia. Minfusticia. https://www.minjusticia.gov.co/Noticias/cons250ltele-al-experto-derechos-de-las-personas-con-discapacidad

Cruces Burga, A. (2015). Derecho a la educación de las personas con discapacidad: nuevos contenidos en el caso de las personas con Síndrome Down. Foro Jurídico, 14, 70-76. http://revistas.pucp.edu.pe/index.php/forojuridico/article/view/13751

Del Águila, L. M. G., García, C. S., \& Ferrer, P. P. (2010). Pablo Pineda: una persona Down, en tierra de nadie. Cuadernos de Pedagogía, 398, 40-45.

Del Rey, A., \& Sánchez-Parga, J. (2011). Crítica de la educación por competencias. Universitas: Revista de Ciencias Sociales y Humanas, 15, 136-146.

Díaz, G. S. (2010). El bajo nivel de capacitación de las personas con discapacidad incide en la inclusión laboral determinada en el art. 42, numeral 33 del Código del Trabajo, en las empresas privadas del cantón Latacunga, de la provincia de Cotopaxi, en el segundo semestre del año 2009 [Tesis de pregrado, Universidad Técnica de Ambato]. Repositorio Digital. https:// repositorio.uta.edu.ec/handle/123456789/1257

Echeita, G., \& Ainscow, M. (2011). La educación inclusiva como derecho: marco de referencia y pautas de acción para el desarrollo de una revolución pendiente. Tejuelo: Didáctica de la lengua y la literatura. Educación, 12, 26-46.

Enamorado, D. E., Leiva, V. L., \& Salguero, M. J. (2014). La capacidad de ejercicio en relación a las personas mayores de edad con capacidad limitada, por adolecer de una enfermedad mental crónica e incurable [Tesis de pregrado, Universidad de El Salvador]. Repositorio Institucional de la Universidad de El Salvador. http://ri.ues.edu.sv/id/eprint/13660/

Fernández, M. T. (2010). La discapacidad mental o psicosocial y la Convención sobre los Derechos de las Personas con Discapacidad. Revista de Derechos Humanos Dfensor, 11, 10-17.

García-Cuevas, E. (2015). La igualdad constitucional y la interdicción de la discriminación. Revista de Derecho UNED, 16, 239-274. https://doi.org/10.5944/rduned.16.2015.15281

González, V. (2018). Interdicción por demencia y otras restricciones a la capacidad jurídica de las personas con discapacidad intelectual y mental, bajo la mirada de la CRPD. Solonik, 3, 101-120. https://issuu.com/fundacionhenrydunant/docs/revista_solonik_n_3_julio_2018

Jurado, C. D. (2014). La ley, jurisprudencia y doctrina frente a los actos realizados por discapacitados mentales absolutos interdictos celebrados en un intervalo lúcido. Revista Cultural Unilibre, 2, 14-25.

Llorens, L. R. (2007). La falta o disminución del discernimiento ¡constituye una incapacidad. Odont. info. http://odont.info/ttulo-la-falta-o-disminucin-del-discernimiento-constituye-una.html

Martínez -Lazcano, A. J., Pérez, E. S., \& Cubides, J. A. (2015). Implicaciones del control de convencionalidad: cumplimiento de la Sentencia Radilla Pacheco versus México y el caso de la masacre de Santo Domingo versus Colombia. Revista Cientifica General José María Córdova, 13(15), 115-141. 
Medina-Pabón, J., Rueda, M., Torres-Villarreal, M., \& Díez, C. (2009). Nuevo régimen de protección legal a las personas con discapacidad mental. Universidad del Rosario.

Mejía Díaz, S. (2007). Falta de determinación legal de los tipos de discapacidad como barreras sociales que llevan a la discriminación y a la exclusión social de la persona discapacitada [Tesis de pregrado, Universidad San Carlos de Guatemala]. Biblioteca del Organismo Judicial.

Melgarejo, E. (2018). El derecho a la educación y la distribución de Centros de Educación Básica Especial-CEBE para niños con sindrome de Down en el Distrito de Los Olivos [Tesis de pregrado, Universidad César Vallejo]. Repositorio Digital Institucional. http://repositorio.ucv.edu.pe/handle/UCV/19915? locale-attribute=es

Molina, J., Nunes, R., \& Vallejo, M. (2012). La percepción social hacia las personas con síndrome de Down: la escala EPSD-1. Educaçao e Pesquisa, 3(4), 949-964.

Naciones Unidas. (1994). Normas Uniformes de las Naciones Unidas sobre la igualdad de oportunidades para las personas con discapacidad. OMS. https://www.who.int/disabilities/ policies/standard_rules/es/

No somos personas con discapacidad, sino con capacidades y habilidades diferentes. (2017). Las Provincias. https://www.lasprovincias.es/economia/empresas/201705/26/somos-personas-discapacidad-sino-20170526134933.html?ref=https:\%2F\%2Fwww.google.com\%2F

Oliver-Sola, M. (2009). Precedentes romanos sobre adopción, tutela y curatela. Dereito, 18(2), 181-220.

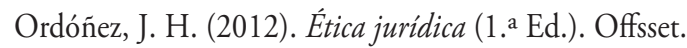

Palací, F., \& Moriano, L. (2003). El nuevo mercado laboral: estrategias de inserción y desarrollo profesional. UNED.

Parra, C. (2003). Borradores de investigación. Población con discapacidad en Colombia. Aspectos sociales, económicos y politicos. Facultad de Jurisprudencia Universidad del Rosario.

Pérez Chávez, D. A. (2014). Sindrome de Down. Revista de Actualización Clínica Investiga, 45, 2357-2361.

Pérez-Carbajal y Campusano, H. (2019). Análisis crítico y constructivo de la declaración del estado de interdicción. En J. A. Domínguez, \& J. A. Sánchez (Coords.), Homenaje al maestro José Barroso Figueroa por el Colegio de Profesores de Derecho Civil, Facultad de Derecho UNAM. UNAM. http://ru.juridicas.unam.mx/xmlui/handle/123456789/12722

Rincón Bustos, M. (2009). Habilidades cognitivas versus habilidades del lenguaje en adolescentes con síndrome de Down. Revista Sindrome de Down: Revista española de investigación e información sobre el Sindrome de Down, 26, 146-155.

Rodríguez, A. (2013). La integración e inclusión escolar de los niños con síndrome de Down [Tesis de pregrado, Universidad de Valladolid]. Repositorio Documental. http://uvadoc. uva.es/handle/10324/3937

Rodríguez, M. (2010). Una relectura de la patria potestad como función tuitiva sobre la persona y bienes de los hijos. Ius et Praxis, 16 (1), 55-84. http://dx.doi.org/10.4067/S071800122010000100003

Ruiz, E. (2001). Evaluación de la capacidad intelectual en personas con síndrome de Down. Revista Síndrome de Down: Revista Española de Investigación e Información sobre el Sindrome de Down, 18(3), 80-88. https://sid.usal.es/7104/8-2-6 
Ruiz, E., Álvarez, R., Arce, A., Palazuelos, I., \& Schelstraete, G. (2009). Programa de educación emocional. Aplicación práctica en niños con síndrome de Down. Revista síndrome de Down, 26 (103), 126-139.

Sevilla Santo, D. E., Martín Pavón, M. J., \& Jenaro Río, C. (2017). Percepciones sobre la educación inclusiva: la visión de quienes se forman para docentes. CPU-e. Revista de Investigación Educativa, 25, 83-113.

Sosa, M. C. (2019). El derecho a la salud de la persona con discapacidad, como un derecho humano. Un análisis del decreto $432 / 97$ para la baja de pensiones y prestaciones de salud [Tesis de pregrado, Universidad Siglo 21]. Repositorio Institucional. https://repositorio.uesiglo21. edu.ar/handle/ues21/17345

Tirado, C. A., \& García, C. E. (2018). Aspectos procesales de la declaratoria de interdicción por discapacidad mental absoluta. Revista Jurídica Mario Alario D'Filippo, 10(20), 154-172. https://doi.org/10.32997/2256-2796-vol.10-num.20-2018-2153

Torres, N., Lissi, M. R., Grau, V., Salinas, M., \& Silva, M. (2013). Inclusión educativa: componentes socio-afectivos y el rol de los docentes en su promoción. Revista Latinoamericana de Educación Inclusiva, 7 (2), 159-173.

Ushca, J. E. (2014). Reformas necesarias al reglamento para la aplicación del régimen disciplinario de las abogadas y abogados en el patrocinio de las causas [Tesis de pregrado, Universidad Nacional de Loja]. Repositorio Digital. https://dspace.unl.edu.ec/jspui/handle/123456789/15575

Valdés, D. (1992). La discriminación arbitraria en el derecho económico. Editorial Jurídica Cono Sur Limitada.

Villa, A. (2013). Un modelo de evaluación de innovación social universitaria responsable. Deusto Publicaciones.

Yuste, C. (1994). Los programas de mejora de la inteligencia. Edit; CEPE.

\section{Legislación}

Congreso de la República de Colombia. (1887). Ley 57 de 1887 artículo 1502, "Con arreglo al artículo 52 de la Constitución de la República, declárase incorporado en el Código Civil el Título III (arts. 19-52) de la misma Constitución”.

Congreso de la República de Colombia. (1887). Ley 57 de 1887, "Con arreglo al artículo 52 de la Constitución de la República, declárase incorporado en el Código Civil el Título III (arts. 19-52) de la misma Constitución”.

Congreso de la República de Colombia. (2009). Ley 1306 de 2009, "Por la cual se dictan normas para la Protección de Personas con Discapacidad Mental y se establece el Régimen de la Representación Legal de Incapaces Emancipados".

Congreso de la República de Colombia. (2018). Ley 1905 de 2018, "Por la cual se dictan disposiciones relacionadas con el ejercicio de la profesión de abogado". https://www.funcionpublica.gov.co/eva/gestornormativo/norma.php?i=87186 